\title{
RETRACTED ARTICLE: Advantages of clinical pathways in severity-based treatment of spondylodiscitis
}

\author{
Lars Homagk $^{1,2}$ (D) - T. Jarmuzek ${ }^{3}$ - N. Homagk ${ }^{1}$ - G. O. Hofmann ${ }^{4}$ \\ Received: 28 February 2019 / Revised: 20 July 2019 / Accepted: 20 August 2019 /Published online: 24 August 2019 \\ (C) Springer-Verlag GmbH Germany, part of Springer Nature 2019
}

The Editor-in-Chief has retracted this article [1] because, owing to a technical error, it was accidentally published after being rejected. Springer Nature apologizes to the authors and to readers. All authors agree to this retraction.
[1] Homagk, L., Jarmuzek, T., Homagk, N., and Hofmann, G.O.; Neurosurg Rev (2019). https://doi.org/10.1007/s10143019-01166-5

Publisher's note Springer Nature remains neutral with regard to jurisdictional claims in published maps and institutional affiliations.

Electronic supplementary material The online version of this article (https://doi.org/10.1007/s10143-019-01166-5) contains supplementary material, which is available to authorized users.

Lars Homagk

info@praxisklinik-dr-homagk.de

Praxisklinik Dr. Homagk, Naumburg, Germany

2 Weißenfels, Germany

3 Centre for Spinal Cord Injuries, BG -Kliniken Bergmannstrost, Halle/Saale, Germany

4 Department of Trauma, Hand and Reconstructive Surgery, Friedrich Schiller University, Jena, Germany 